\title{
Understanding Children's Contributions during Informant Design
}

\author{
Emanuela Mazzone \\ Child Computer Interaction Group \\ University of Central Lancashire \\ Preston (UK) \\ +44 (0)1772 895152 \\ EMazzone@uclan.ac.uk
}

\author{
Janet Read \\ Child Computer Interaction Group \\ University of Central Lancashire \\ Preston (UK) \\ +44 (0)1772 893285 \\ JCRead@uclan.ac.uk
}

\author{
Russell Beale \\ Advanced Interaction Group \\ University of Birmingham \\ Birmingham (UK) \\ +44 (0)121 1413729 \\ r.beale@cs.bham.ac.uk
}

\begin{abstract}
In this paper we describe the analysis of the outcomes of a design session with children. Designing with children is often considered an inspirational activity mainly useful for the designers to get first hand insights of the users' world.

For this study we attempt an analytical approach to the results of a specific design session where children used low-tech prototyping to design the content of an interactive interface for a museum context. This analysis helped to inform the design of the specific product but was also useful to investigate methods of interpreting qualitative data of this kind.

The analysis showed that the design method employed enabled the children to consider design features but also demonstrated that in some areas the children had only a limited understanding. Results from this work will be used to improve, and describe future design sessions.
\end{abstract}

\section{Categories and Subject Descriptors}

H 5.2 [User Interfaces]: Prototyping. Screen Design, UserCentred Design

\section{General Terms}

Measurement, Design, Experimentation, Human Factors.

\section{Keywords}

Design Workshop, Children Users, Interface Design, Prototype, Data Analysis.

\section{INTRODUCTION}

Sanders [7] highlights that traditional design methods mainly use observational research, focusing on what people do, while traditional market research primarily considers what people say and think, through surveys, questionnaires or interviews. Allowing users to take part in design sessions shifts the focus onto what people make, towards an expression of their ideas, thoughts and perceptions that may not emerge form conventional enquiry methods.

The idea behind participatory design (first introduced by Bjerknes et al. [2]) is that users are essentially contributing their

(c) The Author 2008.

Published by the British Computer Society ideas due to them being considered field experts in identifying needs, problems and assets from their personal experiences [4].

There is no single structured way of running design sessions with users; the methods used depend on the design goals and the designer experience who will adapt the different tools and techniques according to each specific context. Focus groups, brainstorming, and prototyping are a few of the techniques that participants can be engaged in when working on designing products.

Contributions from users to the design are critically needed when the users are youngsters, as they differ in cognitive development and communities of practice from adults who typically are the designers and builders of the same products that children will use. When users are to be children, Scaife [8] introduced the term Informant design to refer to children as native informants and experts of their own practice and needs. Therefore the designers consult them at crucial stages of the design process for specific design goals.

A different way to consider children's role in the design is presented in Druin's Cooperative Inquiry (CI) [3], where children are considered as design partners over the whole duration of the design process. Druin identifies three main techniques comprised in the CI method that allow the children as designers to: collect data about the users' environment; to use low-tech prototyping to represent their design ideas; and to explore different technologies to include in the design.

Baek et al. [1] focused on the cognitive characteristics of children to develop a participatory design technique to design children's websites. Techniques normally used in participatory design workshops for adults need to be adapted to the level of the cognitive development of children to facilitate them expressing their ideas and contributing effectively. Baek et al. developed generative toolkits to help children visualise their ideas and create their information architecture for a certain website structure. The results of this generative process are then analysed by the designers to discover users' needs. Although the interpretation of this type of results is always arbitrary, the Baek et al. study shows an interesting attempt on analysing qualitative data and draws useful suggestions for the design.

In most cases the output of design workshops with users is considered inspirational to the actual product implementation, where users provide insights that are essential for the designers to understand user's requirements.

In this paper we describe a design session that used a low-tech prototyping approach for designing educational technology with children as informants. The context was provided by a project on digital technology for educational visits to museums. 


\section{THE PROJECT}

The BEAM Project is one of the projects funded by the Lancashire Digital Development Agency (UK) with the intention of promoting the use of broadband technology to support educational activities. BEAM stands for Broadband Enabled Activities for Museums and it intended to exploit the potential of broadband technologies in providing direct connection between schools and museums so to support educational activities related to the visit to the museum.

According to this aim, the project was designed to assist the students' learning experience throughout the three stages of before, during and after the visit. Specific technology was required to support the children during each stage by allowing them to:

- access to the project website via webcam positioned in the museum to explore the space; register the school visit and plan the visit selecting the curriculum related topics and the supportive technology available on site (Pre-visit);

- record the experience by taking pictures, writing notes or recording comments with digital equipment such as cameras, PDA's, tablet PC, Dictaphones (During-visit);

- $\log$ in the secure personal account created for the specific school visit to access all the rich media files produced during the visit and use them for class activities (Post-visit).

The target user group comprised primary school children and teachers. Different local schools were selected for participation in the design and evaluation cycles over the duration of the projects.

\section{THE METHOD}

The design objective was to provide the children with a coherent experience of their interaction with a range of digital products: in this study the two technologies that required design of specific interfaces were the website and the tablet PC. To gather design ideas for this objective, an Informant Design approach was adopted. The children's contribution was sought to achieve a better understanding of their knowledge of related terms, discover the children's perceptions and experience of the museum context, provide familiarity with the concept of visualisation of contents and information, and discover their understanding of interacting with technology.

This paper will report on the results collected during a design activity exploring contents and interaction of the website.

Two classes of Year 3 children (aged 7 and 8) from the same school were engaged in the one hour activities, one class immediately after the other. A total of 42 children participated in the design sessions with the two researchers. The activities took place in the classrooms, with the teacher and at least one teacher assistant present in each class. For a detailed description of the structure of the method we direct you to Kelly et al. [6]. In this paper we focus on a specific design session and the way we approached the analysis of the data that resulted from the day.

The design activity was intended to gather information about the content for the digital applications. It was in two parts, and relied on the existence of an early prototype. Before any work was done, the children had to be introduced to the context via images and narrative of the museum we were referring to. In the first activity of the design session the children were asked to produce lists of words that they might associate with the application. In the second activity, the children were shown a wire-frame interactive prototype of the product and given blank paper artefacts on which they were asked to add content. With this practice the design team sought insights into the children's perceptions of the context, their knowledge, their preferences, the terms they were familiar with and the topics that were relevant to them.

\subsection{Activity 1}

The first activity was a brainstorming exercise to help children to get into the topic and retrieve information from their previous experience and background knowledge.

Children split in groups of three to five pupils around each table. They were asked to write or draw on post-it notes all the concepts related to their memories of their recent visit to Helmshore Museum: what they had seen, what they had learnt, what they liked about it. The notes were then all collected and grouped according to similarities of topic for each table. Clustering them in this way gave an idea of categories of topic that were relevant for them.

\subsection{Activity 2}

With this design activity we were aiming at getting an idea of the children's concept of navigation, their perception of text, pictures, sound and interaction in the interface.

To give the children an idea of what they would have to design for, we first briefly showed the children the tablet PC and explained how it would be used when they would be walking round in the museum.

Sitting around the same tables as in activity 1 , the children then started creating prototype pages with content and activities that could happen on the tablet PC. Figure 1 depicts a moment of activity 2: the output of the first activity was kept in the middle of the table with all the post-it notes stuck on an A3 sheet and used as a reminder of information.

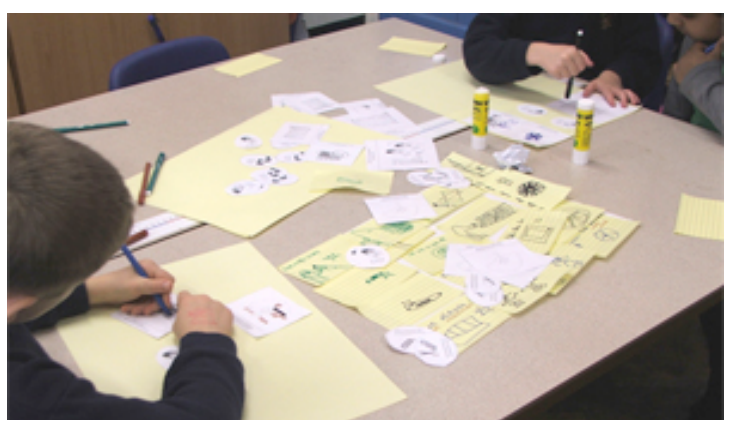

Figure 1. Children creating contents for the interface.

They were provided with blank A3 sheets of paper on which they could stick buttons, windows and write and draw with coloured felt tip pens. They were given four types of contents and four types of buttons which represented possible information and actions to include in the interactivity of the technology. These objects were created in relation to possible educational activities related to the museum visit and the information that would derive from it. The children were provided with four possible types of content according to the different ways of showing information, whether it was written, visual, or multimedia. These were squared cut pieces of paper with a faded image representing the nature of the information as well as a short text underneath:

- Text: "Here you can put some text, what it will be about?"

- Video: "here is a video, what it will show?

- Sound: "here is some sound/voice, what will it be like?" 
- Picture: "here is a picture, what it will be?"

The other class of prompts concerned actions. As they intended to be only prompts for interactivity they were kept quite generic. The buttons were of a rounded shape of the same size with little icons representing the different types of actions:

- Links: "press me and I'll take you to..."

- Doing: "press me and I'll let you do..."

- Writing: "press me and I'll let you write..."

- Cut and paste: "press you and I'll let you stick..."

The children were instructed to write or draw additional information on their interfaces to explain what they wanted to include. Because of the low children-designer ratio present in each session, writing was particularly encouraged in order not to loose much information from possible misinterpretation of the results in the future analysis. For the same reason each group gave a short presentation of their output at the end of the session.

\section{RESULTS}

What resulted from the design sessions was a conspicuous amount of drawings and writing on paper and sticky notes that needed to be analysed to gather information to feed the future design with.

\subsection{Activity 1}

When it came to analyse the results for Activity 1 all the notes produced by the children in each group were already attached to the same A3 sheet, for a total of 10 groups.

We listed all the contents written or drawn in each group and identified six main categories of information that emerged from the children's output. Table 1 shows the number of notes produced by each group for each category of contents.

Table 1. Number of post-it notes on the same topic for each group (a-e for one class, $f-I$ for the other class) in Activity 1

\begin{tabular}{|l|c|c|c|c|c|c|c|c|c|c|}
\hline & a & $\mathbf{b}$ & $\mathbf{c}$ & $\mathbf{d}$ & $\mathbf{e}$ & $\mathbf{f}$ & $\mathbf{g}$ & $\mathbf{h}$ & $\mathbf{i}$ & $\mathbf{I}$ \\
\hline Water Wheel & 4 & 5 & 4 & 4 & 6 & 3 & 4 & 4 & 4 & 4 \\
\hline Machines & 2 & 1 & 5 & - & 3 & 4 & 4 & 4 & 8 & 3 \\
\hline Museum Gallery & 1 & - & 3 & 3 & - & 4 & - & 2 & 2 & 1 \\
\hline Textile Tools & - & 1 & 3 & 3 & - & 1 & 3 & 2 & 4 & 3 \\
\hline Museum History & - & 1 & 1 & - & - & - & - & 3 & - & - \\
\hline Physical Space & 5 & 6 & 4 & 1 & - & - & - & - & - & - \\
\hline
\end{tabular}

\subsection{Activity 2}

For the second activity, although the children were in the same groups as in Activity 1, they tended to work on their own interface, only a few worked in pairs. This resulted in a total of 31 interfaces.

In each interface we looked at how many of each type of content and interaction the children included from the ones provided. In 3 cases they added contents to blank boxes and made little or no use of the pre-defined ones.

Figures 2 and 3 show of how many of each type were included in the total of the interfaces (light coloured columns) and how much additional information was attached to each type (dark coloured columns).

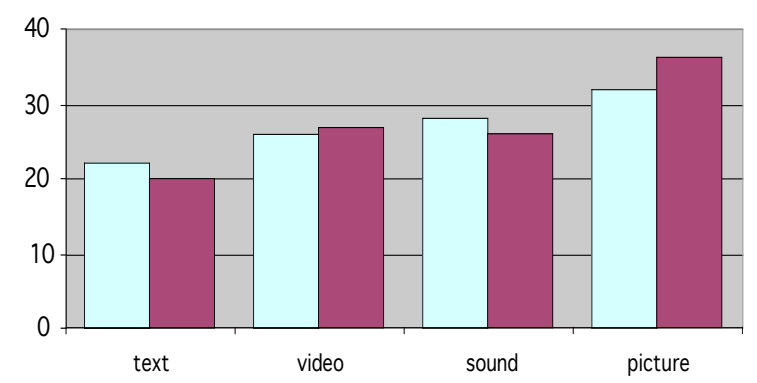

Figure 2. Diagram of the number of "windows" included in the interfaces and the related additional information

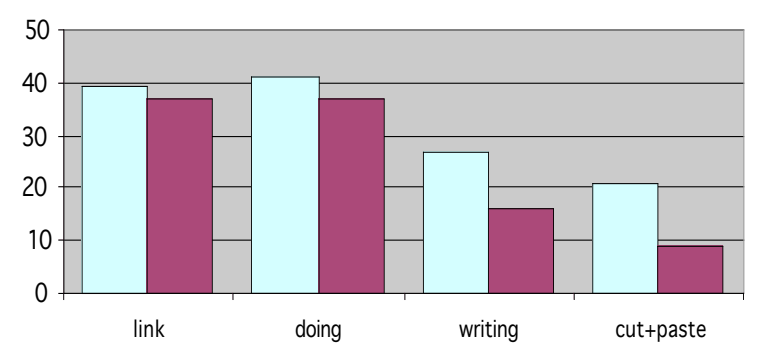

Figure 3. Diagram of the number of "buttons" included in the interfaces and the related additional information

\section{DISCUSSION}

The session provided useful information for the design team according to the goals defined in each activity.

What came out from Activity 1 was an insight of the children's perception about the museum whilst Activity 2 provided a broad understanding of contents and activities related to the topics that were of interest to the children. They also provided original ideas for activities and contents to be included in the future product.

\subsection{Activity 1}

Although the children had last visited the museum several months before the design activity, they clearly remembered general ideas as well as some details and names and managed to produce a varied amount of information.

By looking at the analysis of the results (see Table 1) we noticed that all the groups had one or two categories as the most popular ones and some others as unique to each group. It can also be seen that within each group there are fewer 1s than nil for some categories. It was important to analyse the results dividing them into groups rather than just looking the grand total of the information produced by the children in order to note this behaviour. It is likely that this behaviour was mainly due to the children sitting around the same table and getting inspired by each other's memories. Copying from group mates is a well established behaviour in this sort of activities. In this case it helped generate a larger amount of ideas but limited the variety within the group.

\subsection{Activity 2}

In Activity 2 the children enjoyed producing contents and ideas without focussing much on the navigation structure. Only two groups added an extra screen and put a link between the two screens.

The way the children used the space and the material provided for the design varied considerably (Figure 4 shows two extreme examples). To understand the children's use of the tools provided for the design we paid particular attention to the information added, by writing or drawing, to each "window", 
"button" or directly on the sheet of paper that stood for the background.

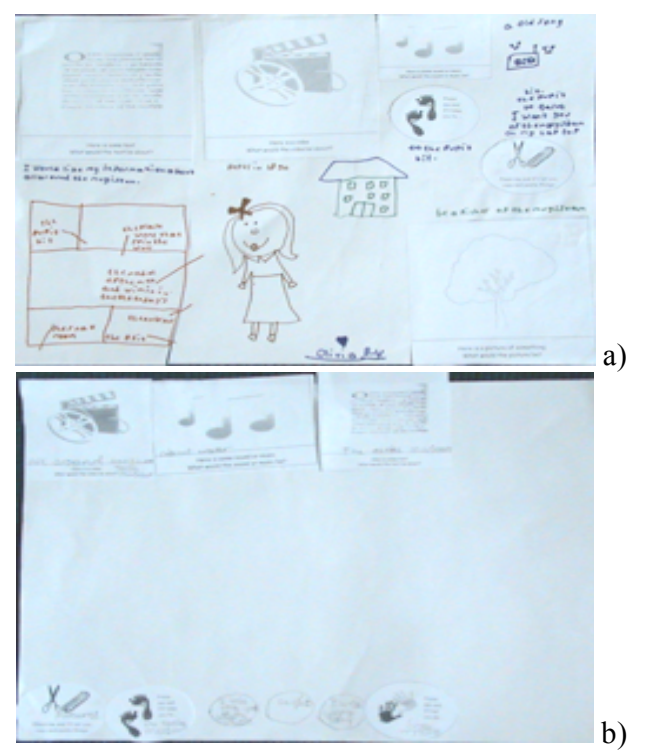

Figure 4. Two examples of children's outputs for Activity 2 with different amount of information added by the children

The diagrams in Figures 2 and 3 give an idea of how much additional information was attached to each type of object. The fact that some of the children did not complete the sentences on the stickers, nor annotated them with drawing, led us to assume that they did not grasp the function of the specific object.

For what concerns the "window" type of objects, all the four types have been used in all the interfaces in a similar amount. Form the diagram it can be noted that the most popular ones are the pictures and the video "windows", where the children added a higher amount of information, more than one per object.

For the "buttons" instead, there is a significant difference between the amount of 'link' and 'doing' types used and the 'writing' and 'cut and paste' types. The 'cut and paste' type is the one with a very low percentage of information added.

Apart from being actions that the children were not particularly interested in, the reason for the little use can be related to the design and description of the buttons themselves that were unclear to the children.

A possible reason for this is related to the tools used as prompts. The faded pictures in the background of the "window" notes were possible cause of ambiguity and confusion in one case, although they did not bias the final results. What they may have caused is that most of the children added writing to the window boxes but not many drawings. They used the space on the background paper to freely draw decorations to the page as well as information related to the contents.

\section{CONCLUSIONS}

The need of a thorough interpretation of the information collected rather than just an inspirational understanding of children perceptions and interests came from the number of children that participated in the activity and produced a considerable amount of outcomes in a short time.

Many studies [3, 5 for example] with young users as designers have a low child-adult ratio: this is to facilitate the adult's understanding and interpretation of the children's contribution. In this study the ratio was particularly high because we were aiming to collect a large amount of information in a limited period of time due to the project time constraints. Also, this was possible due to the nature of the information that was sought in this specific study: we wanted an understanding of children memories and perception of the museum visit, for which quantity had priority on depth of details. The intermittent support of adults seemed not to have affected the children's ease of performing the tasks.

One of the major problems faced in trying to collate and analyse such a varied collection of data is that the children are very likely to spend time reinforcing behaviours (copying key phrases, etc, as demonstrated in the results of Activity 1). In addition, Activity 2 has demonstrated that, despite growing up in a digital world, the children are still not familiar with many common UI elements, and require more grounding in their meaning if they are to contribute more directly to useful designs.

We did find that the analysis of the outputs produced during the session not only provided useful information for the design of the future product, by revealing children insight and perspective, but also about the methods and tools used during the activities.

\section{ACKNOWLEDGMENTS}

Our thanks to Helmshore Primary School, teachers and children for the enthusiastic support provided during the project.

\section{REFERENCES}

[1] Baek, J.-S., Lee, K.-P. (2003) A Study of Cognitive Characteristics of Children's Information architecture Using Participatory Design Technique, Research Papers of Ergonomics for Children and Educational Environment, IEA Technical Committee.

[2] Bjerknes, G., Ehn, P., \& Kyng, M. (Eds.), 1987. Computers and Democracy: A Scandinavian Challenge. Aldershot: Avebury

[3] Druin, A. Cooperative Inquiry: Developing New Technologies for Children with Children. In Proceedings of the SIGCHI conference on Human factors in computing systems (CHI '99) (Pittsburgh, PA, USA, 1999) ACM Press, NY, 1999, 592-599

[4] Greenbaum J. and Kyng, M., (eds.) (1991) Design at Work, Hillsdale, NJ: Lawrence Erlbaum.

[5] Guha, M.L., Druin, A., Chipman, G., Fails, J.A., Simms, S., Farber, A. Working with Children as Technology Design Partners, ACM Communications, Jan 2005, vol.48, no.1, special issue Interaction Design and Children, 39-42

[6] Kelly,R., Mazzone,E., Horton, P., Read, J. "Bluebells: A Design Method for Child-Centred Product Development". in Proceedings of NordiCHI 2006 (Oslo, 2006), ACM

[7] Sanders, E.B.-N. Postdesign and Participatory Culture". In: Proceedings of Useful and Critical: The Position of Research in Design, Helsinki: University of Art and Design

[8] Scaife, M., Y. Rogers, F. Aldrich \& M. Davies (1997). Designing For or Designing With? Informant Design for Interactive Learning Environments. CHI '97, Atlanta, ACM Press. 